\title{
Discutindo a relação entre espaço e aprendizagem na formação de profissionais de saúde
}

Norma Carapiá Fagundes ${ }^{1}$ Teresinha Fróes Burnham²

FAGUNDES, N. C.; FRÓES BURNHAM, T. Discussing the relation between space and learning in the training of health professionals, Interface - Comunic., Saúde, Educ., v.9, n.16, p.105-114, set.2004/fev.2005.

This article discusses the relation between space and learning, as a way of thinking of modifications or curricula innovations, based on demands from practice. It analyzes experiences with communities developed by nursing schools, schools of dentistry and medical schools. The epistemological / methodological proposal is based on the theories of complexity and of multiple references. Analysis revealed significant learning experiences for the subjects and indicated that it is not enough to define new teaching sites; it is necessary to reflect upon practice, so that it may be a reference for questioning and transforming traditional forms of conceiving the curricula. Furthermore, it indicated that rethinking the curricula signifies developing a new relationship with knowledge, which implies in changes in the relations between the university and the diverse forms of knowledge in existence and the recognition of the value of learning (re)constructed in experience. In conclusion, the article stresses that the university should institute mechanisms for listening to what various actors have to say about the practices it develops and invest in a solid cultural education that is critical with respect to the students.

KEYWORDS: Curriculum; training; learning; spaces; education medical.

Discute-se a relação entre espaço e aprendizagem, como uma forma de pensar modificações ou inovações curriculares a partir de demandas da prática. Analisam-se experiências com comunidades desenvolvidas pelos cursos de enfermagem, odontologia e medicina. A metodologia tem como substratos as teorias da complexidade e da multirreferencialidade. O estudo revelou aprendizagens significativas para os sujeitos e trouxe a questão de que não basta definir novos locais de ensino; é preciso exercitar a reflexão sobre a prática, para que esta possa ser uma referência para interpelação e transformação das formas tradicionais de conceber currículo. Revelou, ainda, que repensar o currículo significa o desenvolvimento de uma nova relação com o saber, implicando mudanças nas relações entre a universidade e os diversos saberes existentes e na valorização da aprendizagem (re)construída na experiência. Como conclusão, destaca-se que a universidade deve instituir "escutas" das práticas desenvolvidas e investir numa formação cultural sólida e crítica dos estudantes.

PALAVRAS-CHAVE: currículo; formação; espaços; aprendizagem; educação médica.

*Artigo elaborado a partir de Fagundes, 2003 (Tese de Doutorado em Educação, UFBA).

${ }^{1}$ Professora, Departamento de Enfermagem Comunitária, Escola de Enfermagem, Universidade Federal da Bahia. $<$ fagundes@ufba.br>; <normafagundes@terra.com.br>

2 Professora, Faculdade de Educação, Universidade Federal da Bahia. <tfroesb@ufba.br>

${ }^{1}$ Rua Professor Sabino Silva, 823, apto. 102

Edifício Vivenda Sam Matheus

Jardim Apipema - Salvador, Ba

40.155-250 


\section{Introdução}

A idéia de que o que se aprende tem relação com o local, com a interação entre as pessoas e com o momento, tem sido preconizada por grandes nomes da educação, destacando-se, dentre eles, Anísio Teixeira. Aprofundando essa questão, autores como Fróes Burnham (2000) e Young (2000) discutem que o processo de formação não ocorre somente na escola. Acontece em múltiplos espaços, assim como são múltiplas as aprendizagens que ocorrem em cada um desses espaços. Para esses autores, o que define o sentido da formação profissional é, predominantemente, a relação que se estabelece nos espaços nos quais se materializa a educação (especificamente na área de saúde: sala de aula, laboratórios, serviços de saúde, espaços da comunidade).

Para discutir as possíveis relações entre espaço e aprendizagem, o estudo tomou para análise atividades de ensino junto a comunidades do Distrito Sanitário Barra/Rio Vermelho em Salvador, realizadas por diferentes escolas da área de saúde da Universidade Federal da Bahia, buscando compreender como estas experiências podem contribuir para o desenvolvimento de aprendizagens plurais, extrapolando o limite das puramente instrumentais/ técnico/científicas, hegemonicamente demandadas pelos currículos de formação de profissionais de saúde.

Esta análise toma como base crítica a constatação de que os atuais currículos, ao trabalharem com um modelo de organização que pressupõe a precedência da aprendizagem de referenciais teóricos para depois "aplicá-los" na realidade, reduzem os "espaços da prática" a meros "receptores" de conteúdos fragmentados, estudados em sala de aula. Nesta concepção de organização curricular, os "campos de prática" são percebidos como instâncias que pouco têm a oferecer em termos de articulação de novas aprendizagens e da socialização/produção de novos conhecimentos. É preciso, pois, compreender as circunstâncias nas quais as aprendizagens ocorrem, para que se possa pensar em modificações ou inovações curriculares a partir da estreita relação teoria-prática (Toralles-Pereira, 1997).

O dia a dia do trabalho docente, a participação em comissões de currículo e debates, projetos, eventos, cujo centro da discussão é a formação de profissionais da área de saúde, tem evidenciado que, apesar das particularidades de cada curso (que profissional formar; com que competências; em que cenário sócio-cultural; em que espaço tempo-histórico; para qual mercado de trabalho; com qual currículo), existem questões significativas que dizem respeito ao conjunto dos cursos de formação dos profissionais da área, tais como a fragmentação; o tecnicismo; a separação da formação em "ciclo básico" e "ciclo profissionalizante"; a ênfase na "transferência do conhecimento" do "teórico para o prático"; o descompromisso com os serviços de saúde e com a população usuária desses serviços (Paim, 1994).

Além destas, outras questões que têm recebido pouca atenção nos questionamentos à formação $e$, conseqüentemente, na proposição de experiências curriculares, são os processos relacionais/comunicacionais inerentes à prática profissional, incluindo-se, aí, a multiprofissionalidade, intersetorialidade e interdisciplinaridade que atravessam o campo da saúde. 
Questões como estas demandam uma discussão mais global dos currículos da área, posto que elas estão diretamente relacionadas às formas de se conceber saúde e educação.

$O$ trabalho em comunidades foi tomado como referência para o estudo, por ser este um espaço privilegiado de representação da realidade sanitária $e$ social do País, no qual as questões supracitadas ficam bastante evidenciadas. A comunidade caracteriza-se por ser um espaço em que cruzam diversas referências que vão dar origem a saberes distintos daqueles que circulam nas instituições onde, tradicionalmente, as práticas dos cursos da área de saúde ocorrem. A reflexão sobre o exercício de compartilhar experiências e saberes no trabalho cooperativo pode contribuir para que a universidade repense suas práticas e, assim, encontre novos eixos para os seus currículos, ofertando, aos futuros profissionais, oportunidades de práticas para além de um saber eminentemente técnico. Assim, sentimentos, atitudes, cooperação, solidariedade e responsabilidade social estarão envolvidos num mesmo propósito, colocados como elementos necessários ao processo de aprendizagem (Fróes Burnham, 2000; Ayres, 2002).

Uma das principais motivações para o estudo foi buscar formas de mudanças nos currículos de graduação que não se pautassem apenas na definição e fixação a priori de diretrizes normativas, traduzidas em seqüências rígidas de atividades, às quais os professores e estudantes devem se submeter. Esta busca está referida principalmente às dificuldades encontradas no trabalho em "comissões de currículo", nas quais se percebe que a insistência no imperativo da necessidade de mudar o currículo como um todo e de uma só vez, muitas vezes cria mais "resistências" do que "adesões". Compartilhando dessa preocupação, Fróes Burnham (2000) argüi que pensar o currículo de graduação como um objeto estático e totalmente planejado a priori deixa de ter razão ou sentido na contemporaneidade, em que as grandes e velozes transformações do conhecimento e da tecnologia influem diretamente na organização do trabalho, aqui se inclui o de saúde, que a cada dia se torna mais complexo, heterogêneo e mutável. Esse processo faz com que os cenários estabelecidos para a realização do trabalho envelheçam rapidamente.

Pensar em currículos mais sensíveis às necessidades do trabalho, às demandas localizadas, significa o desenvolvimento de uma capacidade de escuta às práticas curriculares nos espaços em que elas ocorrem e a outros espaços sociais em que se aprende saúde, como fonte de questionamentos e de demandas para o processo de formação. Esta compreensão tem na noção de "espaços de aprendizagem" um importante norte.

Fróes Burnham (2000) denomina como "espaços de aprendizagem", aqueles locais que articulam, intencionalmente, processos de aprendizagem (produção imaterial de subjetividades e conhecimentos - escolas, universidades, institutos de pesquisa) e de trabalho (produção material de bens e serviços - locais de trabalho, agências de serviços, grupos culturais, ações de movimentos políticos e sociais). Para a autora, está existindo, cada vez mais, uma interpenetração entre estas duas formas de organizações de aprendizagens.

A necessidade de uma permanente interação entre as organizações 
especialistas e as não especialistas em aprendizagens tem demandado mudanças nas formas de a universidade se relacionar com outros setores da sociedade. Um dos grandes desafios para isto tem sido o de identificar objetivos comuns e explorar novas formas de parceria e de instituição de espaços de aprendizagem necessários aos processos de formação demandados na contemporaneidade. Uma das justificativas para que a universidade aceite este desafio é o de que o confronto entre as visões de mundo na universidade $e$ as visões encontradas em outros espaços sociais contribui para a formação de novos conhecimentos, saberes e novas idéias para a solução de problemas reais e, reflexivamente, para a concepção de novas formas de construir currículos (Fróes Burnham, 2002).

As práticas curriculares dos cursos de graduação da área de saúde são realizadas em diversos espaços (hospitais, postos e centros de saúde, creches, asilos, espaços da comunidade, além daqueles da própria universidade, como a sala de aula, laboratórios, bibliotecas, entre outros). Cada um deles constitui-se como espaço de inter-relacionamentos distintos que, conseqüentemente, produzirão, também, aprendizagens distintas. Entretanto, o reconhecimento da autonomia (relativa) desses espaços, como locais de articulação de novas aprendizagens e da socialização/produção de novos conhecimentos, não parece muito claro nas formas tradicionais de organização dos currículos.

Para autores como Fróes Burnham (2000) e Young (2000), o que define o sentido da formação profissional é, predominantemente, a relação que se estabelece, nos espaços em que se materializa a educação. Essa maneira de conceber a formação amplia a idéia de aprendizagem para além daquelas estritamente escolares. Pensar em organizações curriculares, tomando como base a concepção de "espaços multirreferenciais de aprendizagem" significa, antes de tudo, o reconhecimento de que os processos de acesso, construção $e$ socialização do conhecimento não ocorrem, apenas, no espaço da escola $e$ nem com base nas formas tradicionais veiculadas pelo sistema escolar. Nesse contexto, o conceito de aprendizagem tende a se ampliar cada vez mais, e a noção de espaços articuladores dessas aprendizagens torna-se fundamental para a criação de novas formas de inteligibilidade e legitimidade dos conhecimentos produzidos.

Na concepção de Young (2000), uma transformação efetiva na forma de conceber o currículo só ocorrerá quando houver mudanças nas relações entre os teóricos da universidade e aqueles acerca dos quais teoriza. Para o autor, um caminho para isto seria o estabelecimento de vínculos mais explícitos entre o aprendizado no trabalho, na comunidade e o aprendizado nas salas de aula. Young vê isso como um reconhecimento de que boa parte das mudanças curriculares não terão, necessariamente, início nas escolas ou nas universidades, mas em outros espaços sociais. Um maior vínculo entre a universidade e outros espaços da vida social, poderia, na percepção do autor, oferecer o contexto para o desenvolvimento de teorias com maior base prática, bem como de práticas com melhor base teórica.

Metodologia

Observar em que medida a "saída" da universidade do seu espaço físico/ 
${ }^{3}$ Estágio Curricular em Rede Básica (Escola de Enfermagem),

Odontologia em Saúde Coletiva (Faculdade de Odontologia) $e$ Introdução à Medicina Social (Faculdade de Medicina).

${ }^{4}$ Além das práticas das disciplinas analisadas, foram também incluídas aí ações de programas como o Projeto UNI (Uma nova iniciativa em saúde financiado pela Fundação Kellogg), do "UFBA em Campo" e da "Atividade Curricular em Comunidade", ambos propostos $e$ coordenados pela PróReitoria de Extensão da UFBA. Estes programas, apesar de não fazerem parte diretamente do objeto do estudo, tiveram destaque na análise, por terem sido amplamente citados pelos sujeitos da pesquisa. acadêmico para outros espaços da sociedade pode contribuir para interpelação e transformação das formas tradicionais de fazer currículo, trouxe grandes desafios para a realização do estudo. A construção de um referencial de análise que ajudasse a compreender as especificidades da relação entre os espaços das práticas de formação (no caso, o trabalho com comunidades) e a construção de aprendizagens significativas, em uma pesquisa com múltiplos sujeitos, com distintos saberes, interesses $e$ perspectivas sobre o trabalho coletivo entre a universidade e a comunidade, trouxe a necessidade de se lançar mão de várias abordagens identificadas no processo como contributivas para a compreensão do objeto de estudo.

Assumir que todo conhecimento humano é relativo, parcial e incompleto foi um aprendizado possibilitado pela incursão no pensamento complexo (Morin, 2000), na abordagem multirreferencial (Ardoino,1998) e na hermenêutica (Heidegger, 1998; Gadamer, 1997).

O trabalho de campo foi realizado no período de abril a junho de 2001, por meio de grupos focais e da observação direta. Foram realizados oito grupos focais, três deles com professores (dos cursos de enfermagem, medicina e odontologia - um com cada grupo específico), outros três com estudantes (seguindo a mesma sistemática dos professores). Foram realizados, ainda, grupos com lideranças comunitárias e com agentes comunitários de saúde.

O critério para seleção dos professores e dos estudantes foi de estar atuando em ou cursando uma das disciplinas selecionadas para o estudo ${ }^{3}$, durante o período do trabalho de campo ou terem dela(s) participado/ cursado até dois semestres antes de 2001.

As lideranças comunitárias selecionadas para o estudo foram aquelas que participam mais diretamente no planejamento, acompanhamento e avaliação das atividades dos estudantes na comunidade. Os agentes comunitários convidados foram aqueles que estavam participando, ou que haviam participado recentemente (até um ano antes), de trabalhos com alunos $e$ professores dos cursos envolvidos, em sua área de atuação.

Obteve-se a autorização dos participantes mediante assinatura de "Termo de Consentimento Livre e Esclarecido". No caso dos agentes comunitários de saúde (ACS), foi solicitada também a autorização das enfermeiras supervisoras e da coordenação do distrito sanitário ao qual os ACS estavam ligados. O projeto de pesquisa foi aprovado pelo Comitê de Ética interno da Faculdade de Educação da UFBA.

Para a análise qualitativa dos dados, foram utilizadas as técnicas de "análise temática" e "análise de enunciação" (Minayo, 1996; Bardin, 1979).

\section{Análise e discussão dos resultados}

A análise do material produzido/recolhido no campo revelou que, na opinião de todos os grupos envolvidos, o maior ganho proporcionado pelo trabalho cooperativo $^{4}$ foi o processo de construção de vínculos mais sólidos, como parte de um novo compromisso firmado entre a universidade e a comunidade. Neste processo, muitos projetos e objetivos comuns foram construídos. As práticas analisadas podem ser consideradas iniciativas que visam, de alguma forma, repensar a inserção da universidade na sociedade, 
pois representam um contraponto à formação enclausurada de profissionais, e uma tentativa de respostas éticas, solidárias, às críticas e pressões de vários setores da sociedade à universidade pública brasileira.

Contudo, questões apontadas pelos representantes das comunidades, estudantes e professores indicam a necessidade de uma permanente reflexão sobre essas práticas para que possam, de fato, contribuir para a instituição de uma universidade mais sensível, cooperativa e produtiva no que se refere à interação com a sociedade.

Especificamente no campo da saúde, nos espaços tradicionais da formação, sobretudo nos hospitais e um pouco menos nos centros de saúde, as hierarquias e as rotinas são muito rígidas. A postura autoritária dos profissionais é em grande parte modelada nestes espaços. Daí a necessidade apontada pelos alunos, de participarem de outros cenários favoráveis ao estabelecimento de relações mais simétricas, em que o efetivo compartilhamento de saberes/práticas, inclusive de vivências de problemas, possibilite a busca e a produção de alternativas voltadas para uma maior articulação teoria/prática; academia/serviço que levem também à construção de conhecimentos necessários à solução dos problemas partilhados. Entretanto, a mudança de foco do ensino em relação a estas questões não é um processo que ocorra automaticamente; a tendência observada no estudo foi a de que a universidade, quando toma o "espaço comunidade" como referência para práticas curriculares, o faz, na maioria das vezes, reproduzindo ou tentando reproduzir os modelos prescritivistas $e$ autoritários que a tem caracterizado.

Observou-se, nas práticas analisadas, a necessidade da instituição de um "saber escutar antes de intervir". Este é um aprendizado que requer uma mudança radical no comportamento habitual da universidade de já chegar ensinando, ordenando, classificando, a partir de uma listagem elaborada previamente, de coisas que devem ser observadas e modificadas.

A percepção da prática, apenas como local de "reconhecimento" de problemas já traduzidos instrumentalmente, visando ao consumo cognitivo de algum conteúdo, deixa de lado a necessidade de pensar, de desentranhar o sentido de uma experiência nova e os caminhos de uma ação por fazer. Ao se abdicar disso, como lembra Chauí (2001), a tendência é repetir, sempre, os modelos adestrados e tomar a prática como uma aplicação mecânica desses modelos sob a forma de táticas e estratégias. A própria idéia da ação como práxis social pode se transformar em pura técnica de agir circunscrita ao campo do provável e do previsível, isto quando vivemos em uma sociedade que está em constante mutação, em que situações inesperadas e imprevisíveis acontecem freqüentemente. Se temos como prática o costume de apenas nos instalarmos de forma segura em nossas teorias e idéias, que nem sempre têm possibilidade de acolher o novo, teremos muita dificuldade de aprender a enfrentar as incertezas do mundo (Morin, 2000). Aprender a lidar com as incertezas, com o imprevisível, traz a necessidade de um certo "luto" da vontade do "domínio absoluto" do outro, da natureza.

A ênfase em problemas e na "transmissão" de informações, ambos sistematizados em outros contextos, fez com que se observasse pouco interesse por parte dos representantes da universidade (estudantes $e$ 
professores) pelo que as pessoas pensam de seus problemas e soluções que buscam espontaneamente, perdendo-se, assim, oportunidades de buscar temas de estudo, de desenvolvimento de novas tecnologias socialmente apropriadas, a partir das soluções encontradas pela população, ou seja, de se buscar novas formas de colaboração, diálogo e interfecundação entre os saberes práticos, tácitos, não sistematizados e saberes sistematizados.

Uma outra questão discutida pelos sujeitos da pesquisa foi a excessiva fragmentação disciplinar dos currículos. Este é, certamente, um dos problemas relacionados a currículos escolares mais discutidos atualmente, sobretudo nas universidades. Tomando-se como exemplo os currículos de graduação, observa-se que, na maioria das vezes, as disciplinas são tratadas de modo reificado, como conteúdos estanques, com pouca ou nenhuma interconexão, tanto entre si, quanto em relação ao mundo concreto e à experiência vivida; quando muito, aborda as práticas de trabalho de forma mecânica, vazia de reflexão. Isto não só dificulta ao aluno uma compreensão mais abrangente do saber historicamente produzido pela humanidade, como, também, contribui para reforçar a visão quase que puramente tecnicista $e$ instrumental que tem caracterizado a educação superior (Fagundes \& Fróes Burnham, 2001).

A fragmentação existente em instituições como a universidade não é casual ou irracional, é deliberada, obedece aos fundamentos do taylorismo que ainda é a regra predominante na organização de nossas instituições (Chauí, 2001). Esta é uma questão fundamental, mas, a nosso ver, não é o único aspecto da fragmentação que precisa ser questionado na formação $e$ no trabalho dos profissionais de saúde; existem outros, cuja tematização $e$ superação é essencial para a transformação desses processos. Um destes aspectos é o da multiprofissionalidade que atravessa este campo. Nas experiências analisadas, não foi observado nenhum esforço de contribuir para o aprofundamento das questões relacionadas ao tema. Este "silêncio" é surpreendente, dada a ênfase que a temática, juntamente com a interdisciplinaridade $e$ a intersetorialidade, vêm tendo nas discussões $e$ propostas de mudanças curriculares na área da saúde.

Um dos prováveis motivos deste "silêncio", na percepção de Peduzzi (1998), é o não compartilhamento da qualidade interativa do trabalho entre os profissionais de saúde. Para a autora, falta a esses profissionais a percepção de que estão trabalhando em interação. E, à medida que não concebem o trabalho como instância interativa, buscam apenas na autonomia técnica individual a possibilidade de se expressar como sujeitos da ação. Assim, a interdependência que existe entre o trabalho dos diversos atores deixa de ser contemplada.

O ensino na graduação em enfermagem tem possibilitado a percepção in loco da pouca articulação no conjunto da assistência à saúde prestada à população, devido, em grande parte, à desintegração entre os profissionais cuidadores. Essa falta de integração é, também, percebida na formação. Nesse campo, percebe-se, ainda, uma carência muito grande de projetos que visem encontrar formas de superar a fragmentação do cuidado em saúde. $\mathrm{O}$ isolamento e o confinamento de cada curso em si mesmo contribui para que os futuros profissionais não percebam a interação de seu trabalho com o dos 
demais trabalhadores da área e de outros setores da sociedade, perdendo-se, assim, como apontam Almeida e Mishima (2001), a oportunidade de formar profissionais mais comprometidos com a superação do "modelo de atenção desumanizado, fragmentado, centrado na recuperação biológica individual e com rígida divisão do trabalho e desigual valoração social dos diversos trabalhos" (p. 151).

Uma outra "demanda" que o trabalho com comunidade traz para o processo de organização curricular, é a necessidade de uma valorização mais explícita dos saberes (re)construídos na experiência.

Os saberes da prática têm uma relação direta com a interação entre as pessoas. Os estudantes referiram-se a diversos tipos de saberes (aprendizagens) articulados nesse processo que podem ser elencados como: 1) melhor capacidade de comunicação (falar e escutar), incluindo-se aí o esforço de encontrar formas para "driblar" a assimetria naturalmente existente entre a linguagem técnica e a linguagem popular; 2) aprender a se relacionar e a acolher o outro; 3) perceber que a população tem seus próprios saberes, portanto a não presumir sempre a ignorância do outro nas questões de saúde; 4) gerir situações que ocorrem no cotidiano do trabalho; 5) resolver problemas criativamente; 6) atentar para uma prática profissional humanizada; 7) compreender de forma mais ampla os limites $e$ as possibilidades da atuação profissional. Estes são aprendizados que, na maioria das vezes, não tinham sido previstos nos objetivos das disciplinas, o que sugere que os professores não lhes prestam muita atenção, mas que os estudantes dão muita ênfase.

Práticas que facilitem a conciliação entre conhecimentos teóricos e conhecimentos forjados na experiência é fundamental para o desempenho dos profissionais de saúde. Tomar decisões que afetam a vida de outras pessoas faz parte da rotina desses profissionais. Neste processo, participam saberes éticos, técnico/científicos e em grande parte saberes da experiência (Bernadou,1996).

Os saberes da experiência (implícitos, tácitos) na concepção de Therrien (1997) são aqueles que verdadeiramente orientam a prática, daí sua grande importância no processo de formação. A reflexão sobre as aprendizagens da prática, a fim de que essas possam ser compartilhadas, tornadas explícitas, requer, como fala Pozo (2002), um planejamento de atividades com esta finalidade, ou melhor, requer que a aprendizagem seja, de fato, objeto de preocupação e estudo nos currículos escolares.

\section{Conclusões}

De acordo com o que foi discutido pelos sujeitos da pesquisa e o diálogo com os outros autores convocados para a reflexão, pode-se concluir que a instituição de formas de "escuta" às práticas poderá trazer subsídios para que a universidade encontre novos eixos para seus currículos, visando à formação de cidadãos socialmente responsáveis e com capacidade de reflexão sobre seu próprio trabalho. Sem esse processo de "escuta", de reflexão, dificilmente ocorrerão mudanças significativas nos processos de formação. Discutir e praticar formas de mudanças nos currículos que não se pautem apenas pela definição e fixação a priori de diretrizes normativas, traduzidas 
em seqüências rígidas de atividades às quais professores e estudantes devem se submeter, é um norte a ser seguido se se quer contribuir para a instituição de uma universidade que intercambia conhecimentos, que acolhe outras visões de mundo, que se preocupa com os problemas do contexto social no qual está inserida.

Em face às incertezas do mercado de trabalho e à volatilidade das informações profissionais que ele reclama, considera-se, como Sousa Santos (1997), que é cada vez mais importante desenvolver com os estudantes uma formação cultural sólida e ampla, quadros teóricos/analíticos gerais, uma visão global do mundo e de suas transformações, de modo a desenvolver o espírito crítico, a criatividade, a disponibilidade para inovação, o desejo de aprender, a atitude positiva perante o trabalho individual e em equipe e a capacidade de negociação que os preparem para enfrentar, com êxito, as exigências cada vez mais sofisticadas do mundo do trabalho.

É, neste sentido, que Demo (1998) chama a atenção para o lugar simbólico que a universidade ocupa, do qual ela pode enxergar a possibilidade, a força e o valor estratégico de espaços diferenciados de aprendizagem que, ao serem vivenciados, ativam o potencial transformador dos sujeitos implicados, na direção de um entendimento da relevância do conhecimento como algo que não apenas conhece as coisas, e sim como algo que pode mudar as coisas.

Repensar o currículo, significa, sobretudo, o desenvolvimento de uma nova relação com o saber. Neste contexto, o professor não pode ser visto apenas como distribuidor e os alunos, como receptores do que foi produzido alhures. Uma outra relação com o saber implica, necessariamente, uma redefinição profunda desses papéis. As questões da relação pedagógica, do compartilhamento dos saberes, do trabalho crítico e reflexivo sobre o conhecimento é que definirão, segundo Nóvoa (2000), mudanças significativas nos currículos e na universidade como um todo.

\section{Referências}

ALMEIDA, M.C.P.; MISHIMA, S.M. O desafio do trabalho em equipe na atenção à Saúde da Família: construindo "novas autonomias" no trabalho. Interface - Comunic., Saúde, Educ., v. 5, n. 9, p.150-3, 2001.

ARDOINO, J. Abordagem multirreferencial (plural) das situações educativas e formativas. In: BARBOSA, JG. (Org.) Multirreferencialidade nas ciências e na educação. São Carlos: EdUFSCar, 1998. p.24-42.

AYRES, J.R.C.M. Práticas educativas e prevenção de HIV/AIDS: lições aprendidas e desafios atuais. Interface - Comunic., Saúde, Educ., v. 6, n.11, p.11-23, 2002.

BERNADOU, A. Savoir théorique et savoir pratiques. L'exemple medical. In: BARBIER, J. M. (Dir) Savoirs thériques et saviors d'action. Paris: PUF, 1996. p.65-84.

CHAUÍ, M.S. Escritos sobre a universidade. São Paulo: Editora UNESP, 2001.

DEMO, P. Extensão como pesquisa. UFBA em campo 1996-1998: uma experiência de articulação ensino/ pesquisa e sociedade. Universidade Federal da Bahia, Pró-Reitoria de Extensão, p.19-22, 1998.

FAGUINDES, N. C. Em busca de uma universidade outra: a instituição de "novos" espaços de aprendizagem na formação de profissionais de saúde. 2003. Tese (Doutorado) - Faculdade de Educação, Universidade Federal da Bahia, Salvador.

FAGUNDES, N.C; FRÓES BURNHAM, T. Transdisciplinaridade, multirreferencialidade e currículo. Rev. 
FACED, n.5, p.39-55, 2001.

FRÓES BURNHAM, T. Sociedade da informação, sociedade do conhecimento, sociedade da aprendizagem: implicações ético-políticas no limiar do século. In: LUBISCO, N.; BRANDÃO, L. (Org.) Informação e informática. Salvador: Edufba, 2000. p.283-307.

FRÓES BURNHAM, T. Cidadania, globalização e tecnologias na (in)formação do trabalhador. 2002. (Mimeogr.).

GADAMER, H. G. Verdade e método. Petrópolis: Vozes, 1997.

HEIDEGGER, M. Ser e tempo. Petrópolis: Vozes, 1998. parte I.

MORIN, E.A epistemologia da complexidade. In: MORIN, E; MOIGNE, J. L. A inteligência da complexidade. 2.ed. São Paulo: Peirópolis, 2000. p.45-137.

NÓVOA, A. Universidade e formação docente. Entrevista. Interface - Comunic., Saúde, Educ., v.4, n.7, p.129-38, 2000 .

PAIM, J.S. Recursos humanos em saúde: problemas crônicos e desafios agudos. São Paulo: Faculdade de Saúde Pública, USP, 1994.

PEDUZZI, M. Equipe multiprofissional de saúde: a interface entre trabalho e interação. 1998. Tese (Doutorado) - Faculdade de Ciências Médicas, Universidade Estadual de Campinas, Campinas.

POZO, J.I. Aprendizes e mestres: a nova cultura da aprendizagem. Porto Alegre: Artmed, 2002.

SOUSA SANTOS, B. Pela mão de Alice: o social e o político na pós-modernidade. 4.ed. São Paulo: Cortez, 1997.

THERRIEN, J. Saber de experiência, identidade e competência profissional: como os docentes produzem sua prática. Contexto Educ., n.48, p.7-36, 1997.

TORALLES-PEREIRA, M. L. Notas sobre educação na transição para um novo paradigma. Interface Comunic., Saúde, Educ., v.1, n.1, p.51-8, 1997.

YOUNG, M. F. D. O currículo do futuro: da "nova sociologia da educação" a uma teoria crítica do aprendizado. Campinas: Papirus, 2000.

FAGUNDES, N.C.; FRÓES BURNHAM, T. Discutiendo la relación entre espacio y aprendizaje en la formación de profesionales de la salud, Interface - Comunic., Saúde, Educ., v.9, n.16, p.105-14, set.2004/fev.2005.

Discute la relación entre espacio y aprendizaje, como una forma de pensar modificaciones o innovaciones curriculares a partir de demandas surgidas en la práctica. Analiza experiencias con comunidades desarrolladas por los cursos de enfermería, odontología y medicina. La metodología tiene como sustratos las teorías de la complejidad y de la

multireferencialidad. El análisis les reveló importantes aprendizajes a los sujetos y trajo la cuestión de que no basta definir nuevos locales de enseñanza, es necesario ejercitar la reflexión sobre la práctica, para que esta pueda ser una referencia para la interpelación y la transformación de las formas tradicionales de concebir el currículum. Reveló, también, que repensar el currículum significa el desarrollo de una nueva relación con el saber, que implica cambios en las relaciones entre la universidad y los diversos saberes existentes y en la valorización del aprendizaje reconstruido en la experiencia. Como conclusión, se destaca que la universidad debe instituir "escuchas" de las prácticas desarrolladas e invertir en una formación cultural sólida y crítica de los estudiantes.

PALABRAS CLAVE: Curriculum; formación; espacio; aprendizaje; educación médica.

Recebido para publicação em 18/05/04. Aprovado para publicação em 30/09/04. 